\title{
Research Paper Writing Strategies of Professional Japanese EFL Writers
}

\section{Kazuko Matsumoto}

Four Japanese university professors were interviewed on their processes and strategies for writing a research paper in English as a Foreign language (EFL). The results show that these professional EFL writers use strategies similar to those used by skilled native English and proficient ESL writers as reported in previous studies, have an explicit view of writing as a nonlinear dynamic process and as a way of discovering meaning and ideas, supplement writing at the computer with writing with pen and paper, and basically do not rely on L1 Japanese in the EFL writing process. It was also found that their L2 research paper writing process is perceived as virtually equivalent to their L1 counterpart, which suggests that already existing $L 1$ writing strategies transfer to $L 2$ writing.

\section{Introduction}

Recent writing process research has shown marked differences in the ways skilled and unskilled native English writers go about their writing (Bridwell, 1980; Faigley \& Witte, 1981; Perl, 1979; Pianko, 1979; Sommers, 1980; Stallard, 1974; Wall \& Petrovsky, 1981). Similarly, studies have also highlighted differences between skilled and unskilled ESL writers in their composing behaviors and the strategies they employ in the L2 writing process (Lay, 1982; Raimes, 1985; Zamel, 1983). The findings of these L1 and L2 writing process studies are, in general, remarkably similar across languages. First, skilled and unskilled writers differ in prewriting activities. Unskilled writers spend only a short time on planning before beginning to write, and tend to adhere to the outline or plan that was originally made, rarely changing that plan in the writing process. Better writers, on the other hand, spend more time on planning, and change and revise the original plan flexibly and freely whenever they have come up with a new idea in the writing process. That is, skilled writers' plans are flexible, whereas unskilled writers' plans are rather fixed (Pianko, 1979; Raimes, 1985; Sommers, 1980; Stallard, 1974; Zamel, 1983). Second, the two groups differ in revision activities. Unskilled writers rarely do meaning-changing revisions. They take pauses so frequently in the composing process, paying attention largely to the correction of surface errors of grammar, spelling, and punctuation (i.e., editing) to avoid any surface-level mistakes from the beginning that they tend to lose the flow of meaning throughout the text in the writing process (Perl, 1979; Wall \& Petrovsky, 1981; Zamel, 1985). For proficient writers, on the other hand, the 
primary concern is the development and formulation of ideas, and the correction of surface grammatical features should be an issue only near the end of the writing process. That is, skilled writers primarily pay attention to ideas and the overall content rather than to the form, dealing with larger chunks of discourse without worrying about minor formal aspects and delaying editing until the end of the process (Bridwell, 1980; Faigley \& Witte, 1981; Raimes, 1985; Zamel, 1983). Third, the views of the writing process differ between the groups. Unskilled writers generally view writing as a straightforward expansion of the original plan, that is, a simple linear process, whereas skilled writers view writing as a nonlinear, creative, generative process whereby they discover new ideas, explore, and formulate those ideas (Perl, 1979; Zamel, 1982).

Moreover, other studies have demonstrated similarities between the L1 and L2 composing processes. Jones and Tetroe (1987), for example, looked at Spanish-speaking ESL writers generating texts in Spanish and ESL; they found that the quality of planning transfers from L1 to L2 and thus certain aspects of a writer's L1 writing process transfer to that person's L2 writing process. In an analysis of advanced ESL learners with differing L1 backgrounds composing in their respective L1s and ESL, Hall (1990) showed that the students' revisions were strikingly similar across languages, suggesting use of a single system in revising across L1 and L2. Further, Arndt's (1987) study with Chinese-speaking graduate-level ESL students also revealed that the processes and strategies of each individual writer remain consistent across L1 and L2 composing (compare Lay, 1982). These studies seem not only to provide evidence for transfer of already existing L1 writing strategy to L2 writing (compare Berman, 1994), but also to suggest the possibility of "composing universals" that go beyond the likeness of L1 and L2 writing (Krapels, 1990, p. 53).

The study reported in this article was an attempt to explore and describe research paper writing behaviors and strategies of professional Japanese EFL writers. More specifically, the following research questions were addressed: (a) What processes do professional EFL writers follow, and what strategies do they use in various stages of the research paper writing process? (b) Do the writers use L1 in L2 research paper writing? If so, when and for what purpose is their use of L1? (c) Do the writers follow the same process and use the same strategies when they write in L1 and in L2? If not, how are the L1 and L2 writing processes different? (d) What are the writers' views of L1/L2 research paper writing and writing in general? and (e) How did the writers acquire native-like L2 writing skills and proficiency? 


\section{Methodology}

\section{Interviews with Japanese Professors}

The data were collected by interviewing four Japanese university professors teaching in Japan. All are well-known male researchers in the humanities in their mid-30s to mid-40s. They all hold doctoral degrees from American universities and have published articles widely both in English and Japanese in their own fields. All of them started learning EFL at the age of 13 during their first year of junior high school, which the Japanese Ministry of Education requires of every student. They then continued to learn EFL as senior high school students, university undergraduate students, and graduate students in Japan. Three of the professors had taught at the university or college level in Japan before coming to the United States for doctoral studies, whereas the remaining one started teaching only after he returned to Japan from his PhD study at an American university. None of them had lived in English-speaking countries for more than two months before they started to: work for doctoral degrees in the US; the average length of their stay in the US was 3.5 years.

The informants were contacted directly by telephone concerning the possibility of serving as informants for this study. Because one of the five professors who were originally in my list of "best" informants declined to participate, this study ended up analyzing four professors' research paper writing strategies. The interviews were conducted in Japanese for approximately one hour in each professor's office, and were audiorecorded for later analysis. The interviews were semistructured, that is, although they centered around the five research questions stated above, the informants were given opportunities to provide freely any information concerning their writing habits and behaviors. The data were not transcribed, because the interactional aspect was not the focus of this study; thus the qualitative analysis was done solely by listening to the tape and taking detailed notes.

\section{Results}

\section{Professors' Research Paper Writing Strategies}

As a result of the analysis of the interview data, some of the distinctive research paper writing strategies and behaviors common to these professional EFL writers have been identified. The results follow with illustrative excerpts from the professors' oral self-reports, each of which has been translated into English from Japanese.

\section{Planning}

The professors reported that in the planning stage they usually first decide, at least roughly, to which journal they will send the paper, and begin to write with a specific audience in mind. They all emphasized the importance of 
being well aware of specific readers in every stage of the L2 writing process. As Professor K says:

It is almost impossible for me to write a paper without thinking of any specific audience who will read the paper after it is accepted and published. Each journal has its own readers, and we must take into consideration the characteristics of the audience, their educational level or native-language background, for example. If the readers are a general audience without much familiarity with the topic of the paper, we must try not to use, or at least try to explain, highly technical vocabulary to aid their comprehension. Even when writing to professional researchers or scholars in a specific field, each journal has its own specific audience: for example, the readers of Journal A, which usually publishes qualitative studies, might not be familiar with highly technical statistical analyses in experimental studies. It is significant that you first survey the characteristic features of each journal you are interested in the planning stage.

All the professors interviewed in this study use word processing for planning and invention; they write down whatever comes to mind on the selected topic in the prewriting stage while organizing the generated ideas on the screen. More specifically, one of these sophisticated writers depends solely on word-processing, whereas three of them usually supplement wordprocessing with handwriting for effective brainstorming. Their planning/prewriting usually takes the following form: they first decide on the title of the paper, which is usually tentative, and then make a rough outline by setting up such sections as the introduction, discussion, and conclusion, working on planning what will be said and which references will be quoted in each section, for example. The writers all pointed out that their plans, being so tentative, never fail to be changed once they begin to write, often leading them to alter the original plan completely during the composing process.

\section{Composing with a Word-processor}

All of the professors responded that they write research papers using a word-processor. More specifically, they compose at the computer in various stages of the L2 writing process, including the planning stage as shown above; they think and create and revise ideas while composing and revising at the computer. They do not usually just type on the screen the paper already composed with pen and/or typewriter, nor do their composing processes involve L1-into-L2 translation. The professors reported, however, that although they primarily use the compose-at-the-computer strategy, they do not rely on word-processing alone in the EFL writing process. Evidently, although appreciating the advantages, they noted certain limitations of com- 
puter-writing, which are largely concerned with the visual-spatial constraint placed on the computer screen, such as difficulty in locating information and difficulty in appropriate reordering of text (Case, 1985; Haas, 1989; Haas \& Hays, 1986; Lutz, 1987). Referring to the limitations of computer-writing, Professor T says:

I have been enjoying writing on the computer. Writing with a wordprocessor is certainly convenient, especially it makes revisions almost instantaneous. But, at the same time, I have also come to feel disadvantages of working with the computer. I often feel that I am compelled to spend more time than when I used to write with pen and typewriter only, on the formal or surface aspects of writing such as punctuation and spelling, and word- or phrase-level options, unnecessarily looking for formal perfection, in a sense. So I make it a rule not to rely on the computer screen alone recently; I try to use pen and paper, especially in the planning and revising stages because it is often difficult, although not impossible, to do effective global-level planning and revision, for example, moving a whole paragraph, when writing with word-processing, especially working on a long paper.

\section{Revising}

The two major strategies these professional writers employ in the L2 writing process are the pay-attention-to-content strategy and the multiple-revision strategy. The writers report that they continue to compose at least one section of the paper in their initial writing, paying attention only to the content of the paper without worrying about the formal aspects (Zamel, 1983). They do not spend too long on a single portion, but continue to type in words, spending a relatively short time, and always come back to these points for revision. That is, they try to refine the paper gradually or make it better and complete through multiple and recursive revision instead of trying to do so instantaneously at the initial composition stage, although one of the writers reported that when working on a short paper he sometimes just types in what he has already composed in his mind followed by very few substantial revisions.

While composing using word-processing, the professors employ several specific strategies. For instance, they will put a special mark, such as an asterisk, on the screen, instead of referring to a dictionary, when they cannot immediately find an appropriate word or phrase or feel unsatisfied with their wording. In this way they can come back to the marked portions later for revision (Zamel, 1983). This allows them to ignore surface feature problems and deal with the more fundamental problems of content and depth. Also, they invariably compose using a single style such as the APA style, mechanically changing it in the final editing to the style required by the specific journal they have in mind, so that the inconvenience of using an 
unfamiliar style will not hinder the successful development of ideas. In addition, whenever coming up with a new idea while composing or revising, they also write it down on the screen with a special marking so that they can come back later for a decision regarding its incorporation in the paper. In general, they use the delete-rather-than-add strategy in the revising process: they try to delete already composed materials rather than adding new information through multiple revisions, which means that they try to put down as many ideas as possible at the initial composing stage. Their multiple revisions, all of the writers reported, are done not only on the computer screen but also on the printouts, mainly in order to solve the problems associated with computer writing, as indicated above.

\section{Use of $L 1$ in $L 2$ Writing}

None of the interviewed professors reported incorporating L1-to-L2 translation into his research paper writing processes, that is, write in Japanese first and then translate the text into English. These professional writers do not use Japanese once they have started to write in English, although they may do so while brainstorming and generating ideas on the topic in the prewriting stage (compare Cumming, 1989; Lay, 1982). They generally continue to think in English, rather than relying on Japanese; whenever they are in need of some English expressions to express their thoughts accurately and cannot do so in the process, they just write down other English expressions that approximate the meaning, underlining or marking those expressions on the computer screen. Later they return to these parts for revision. As Professor S puts it:

Because the vocabulary used in research paper writing in a specific field is actually very limited, it is not even necessary to consult a dictionary, although I might have to do so in other types of writing. In many cases reading papers you are planning to quote and include in the reference section will solve the vocabulary problem. There are certain expressions that are useful and frequently used in research paper writing such as "The purpose of this paper is to ..." and "Given the findings of this study, we can conclude that ..." I think memorizing such phrases surely helps especially beginners like undergraduate or master's level students ... I write an English paper while thinking in English. Clearly it interferes with my English writing to use Japanese or incorporate Japaneseinto-English translation.

\section{L1 Writing Process versus L2 Writing Process}

The interview data reveal that these professional EFL writers follow the same process and use the same strategies across L1 and L2 writing (Arndt, 1987; Hall, 1990; Jones \& Tetroe, 1987). They generally follow the same procedure each time they write a research paper in Japanese, and that same procedure 
is in turn employed in every EFL research paper. All the writers reported that they transfer strategies they acquired in Japanese research paper writing to English research paper writing. Importantly, two of the writers indicated that in other nonacademic writing tasks they might not use the same processes across L1 and L2 writing (compare Silva, 1992). Concerning the relationship between L1 and L2 writing, Professor K says:

I do not think writing a paper in English is fundamentally different from writing a paper in Japanese. I have written lots of papers in Japanese, which I feel have helped me a great deal to write good English papers. It seems that I have learned certain indispensable nonlinguistic strategies that are needed to produce cohesive writing. And apparently I have been successfully applying those acquired strategies and knowledge to English research paper writing so far. I feel that there is something essential or fundamental about writing whether you write in Japanese or in English, or probably in Chinese or in Spanish, which is independent of specific languages ... I want to emphasize here that if you want to be a good second language writer, you have to be a good native language writer in the first place.

\section{Professors' Views on Writing}

The professors' views on writing in L1/L2 and writing in general were similar. That is, they view writing as a process that is not linear, but recursive and dynamic, whereby we create ideas, meaning, and content, that is, a process of thinking and creating ideas and making our own thoughts more accurate and precise (Zamel, 1982). Their view of writing as "the use of language to explore beyond the known content" (Taylor, 1981, p. 4) is explicitly expressed in Professor T's report:

Whenever I feel reluctant to write but have to write as the deadline approaches, for example, I just turn on the computer and type in English words on the screen. This is important. Surprisingly, the moment I do so, I often find new ideas instantly develop. As far as my own experiences are concerned, this is also true of Japanese writing. The moment I write in Japanese using a word-processor or the moment I put pen on the blank sheet of paper before me, my thoughts and ideas develop, half to my surprise. That is, the important thing is to take an action ... begin writing, without worrying about whether you will be able to write well or not. It is through the act of writing that you can explore ideas and meaning.

\section{Professors' Acquisition of L2 Writing Skill}

One of the commonly held views of writing among these professional EFL writers is that learning to write is a skill-building activity, and therefore 
writing ability can improve as a result of practice whether one writes in L1 or L2. All of them reported that repeated practice has enabled them to become more effective writers.

Two of the professors reported that they have been making efforts to use a variety of "mature" constructions, that is, to produce "syntactically mature," "propositionally dense" sentences that are characteristic of professional writing, avoiding, for example, overuse of simple sentences connected by coordinating conjunctions such as and. In addition, it was revealed that all the writers employ the edit-for-oneself strategy. They report that their papers do not often undergo native speakers' editing before being submitted to particular journals; only occasionally do they depend on native speakers for editing. The editing of the paper, that is, polishing, is usually done on the printouts at the final stage of the writing process; editing is done once they are satisfied with the content of the paper, and again at least a few days or a week later. They stressed the importance of a delay between the first editing and the second, commenting that such a delay will enable the writers to see their texts with new eyes, being more distant from, and thus more critical of, their own work.

The writers' secrets for having acquired a native-like L2 writing skill seem to be summarized in Professor M's self-report:

I rarely ask native English speakers to edit my paper although I used to do so previously. Especially, I do not like my style to be changed by another person's, even native speaker's, editing. I have my way of writing a paper as a nonnative writer of English, and I have confidence in it.

This confidence I have acquired by writing papers, that is, I believe writing improves by writing. I view writing as a skill that can undoubtedly improve through practice. Of course, writing also improves by reading, by picking up useful expressions to be used in writing and input them into your brain for future use, whenever possible ... Extensive reading will also help you to acquire a feel for a smooth flow of information in your writing. One of the problems with nonnative writing is lack of this smooth flow of information, and I know even many Japanese professors' EFL writing has this drawback. A sentence is itself a perfectly well-formed one, but it stands somehow independently from the previous or the next one. In order to be able to write in a smooth manner, you have to write and read repeatedly until you get intuitions for smooth writing.

\section{Conclusion}

This study identifies some important secrets of professional Japanese EFL writers' research paper writing processes and strategies. These highly proficient L2 writers uniformly employ strategies similar to those reported in 
earlier studies to be used by skilled L1 writers and proficient ESL writers (Sommers, 1980; Stallard, 1974; Zamel, 1985). Further, the results showed that they perceive the L1 writing process and the L2 counterpart as virtually identical, employing similar strategies across L1 and L2 writing processes, a fact that is also consistent with the findings of previous research (Arndt, 1987; Hall, 1990; Zamel, 1985). This suggests that, as pointed out by one of the professors interviewed, there must exist something fundamentally common to any act of writing, regardless of the language, that is, something nonlinguistic, but cognitive-strategic that helps writers to meet the goal of producing effective and cohesive writing (Taylor, 1981). ${ }^{2}$ Evidently, given previous research findings, it is these strategies that less proficient writers lack and that may be taught to such writers through classroom instruction. I hope that future research will be devoted to the exploration of possible universals underlying both L1 and L2 writing, and possibly any act of composing.

\begin{abstract}
Notes
${ }^{1}$ Interviewing is one of the introspective methods that have been used to date in L2 research to elicit learner strategies along with think-aloud tasks, questionnaires, and diary keeping. This study is concerned with non-task-based retrospective verbal self-report data on both learning strategies and learners' metacognitive knowledge about L2 learning (compare Wenden, 1991). See Matsumoto $(1993,1994)$ for a detailed discussion of taxonomies of introspective methodologies and verbal-report data in L2 research. Also see Matsumoto (1987, 1989, in press) for the role of retrospection in L2 learning processes. For an introductory account of learning strategies research, which is of current interest to L2 researchers, see Cohen (1990), O'Malley and Chamot (1990), Oxford (1990), Wenden (1991), or Wenden and Rubin (1987).

${ }^{2}$ Kaplan $(1972,1983)$ argues that writing style varies according to linguistic and cultural background. In this study, which is concerned with the informants' perceptions of writing, not observation or evaluation of their written products, I found no evidence of existence of cultural thought patterns or contrastive rhetoric in the interview protocols. Of course this does not mean that the four professors do not have culturally and linguistically influenced styles, and, moreover, we could assess their styles only by seeing their writing. There might also be a possibility that such claims will not hold of such highly-advanced sophisticated EFL writers as the informants of this study. They might have already conquered cultural barriers that would otherwise have produced L1-L2 stylistic and perceptual variations.
\end{abstract}

\title{
The Author
}

Kazuko Matsumoto is an associate professor of Applied Linguistics at Aichi University of Education, Japan (1 Hirosawa, Igaya-cho, Kariya, Aichi 448, Japan; e-mail: kzmatsum@auecc.aichi-edu.ac.jp). Her research interests and publications are in both L1 and L2 research, ranging from Japanese syntax and discourse analysis to second language writing, classroom-based studies, research methods, and learning strategies.

\section{References}

Arndt, V. (1987). Six writers in search of texts: A protocol based study of L1 and L2 writing. ELT Journal, 41, 257-267.

Berman, R. (1994). Learners' transfer of writing skills between languages. TESL Canada Journal, $12(1), 29-43$. 
Bridwell, L. (1980). Revising strategies in twelfth grade students' transactional writing. Research in the Teaching of English, 14, 197-222.

Case, D. (1985). Processing professional words: Personal computers and the writing habits of university professors. College Composition and Communication, 36, 317-322.

Cohen, A. (1990). Language learning: Insights for learners, teachers, and researchers. New York: Newbury House.

Cumming, A. (1989). Writing expertise and second-language proficiency. Language Learning, $39,81-141$.

Faigley, L., \& Witte, S. (1981). Analyzing revision. College Composition and Communication, 32, $400-414$.

Haas, C. (1989). How the writing medium shapes the writing process: Effects of word processing on planning. Research in the Teaching of English, 25, 181-207.

Haas, C., \& Hays, J.R. (1986). What did I just say? Reading problems in writing with the machine. Research in the Teaching of English, 20, 22-35.

Hall, C. (1990). Managing the complexity of revising across languages. TESOL Quarterly, 24, 43-60.

Jones, S., \& Tetroe, J. (1987). Composing in a second language. In A. Matsuhashi (Ed.), Writing in real time: Modelling production processes (pp. 34-57). Norwood, NJ: Ablex.

Kaplan, R. (1972). Cultural thought patterns in inter-cultural education. In H.B. Allen \& R.N. Campbell (Eds.), Teaching English as a second language: A book of readings (2nd ed., pp. 294-310). New York: McGraw-Hill.

Kaplan, R.B. (1983). Contrastive rhetorics: Some implications for the writing process. In A. Freedman, I. Pringle, \& J. Yalden (Eds.), Learning to write: First language/second language (pp. 139-161). London: Longman.

Krapels, A.R. (1990). An overview of second language writing process research. In B. Kroll (Ed.), Second language writing: Research insights for the classroom (pp. 37-56). Cambridge: Cambridge University Press.

Lay, N.D.S. (1982). Composing processes of adult ESL learners: A case study. TESOL Quarterly, $16,406$.

Lutz, J.A. (1987). A study of professional and experienced writers revising and editing at the computer and with pen and paper. Research in the Teaching of English, 21, 398-421.

Matsumoto, K. (1987). Diary studies of second language acquisition: A critical overview. Journal of the Japan Association for Language Teaching, 9, 17-34.

Matsumoto, K. (1989). An analysis of a Japanese ESL learner's diary: Factors involved in the L2 learning process. Journal of the Japan Association for Language Teaching, 11, 167-192.

Matsumoto, K. (1993). Verbal-report data and introspective methods in second language research: State of the art. RELC Journal, 24, 32-60.

Matsumoto, K. (1994). Introspection, verbal reports, and second language learning strategy research. Canadian Modern Language Review, 50, 363-386.

Matsumoto, $\mathrm{K}$. (in press). Helping L2 learners reflect on classroom learning. ELT Journal.

O'Malley, J.M., \& Chamot, A.U. (1990). Learning strategies in second language acquisition. Cambridge: Cambridge University Press.

Oxford, R.L. (1990). Language learning strategies: What every teacher should know. Englewood Cliffs, NJ: Newbury House.

Perl, S. (1979). The composing processes of unskilled writers. Research in the Teaching of English, $13,317-336$.

Pianko, S. (1979). A description of the composing processes of college freshmen writers. Research in the Teaching of English, 13, 5-22.

Raimes, A. (1985). What unskilled ESL students do as they write: A classroom study of composing. TESOL Quarterly, 19, 229-258.

Silva, T. (1992). L1 vs. L2 writing: ESL graduate students' perceptions. TESL Canada Journal, 10, 27-48. 
Sommers, N. (1980). Revision strategies of student writers and experienced adult writers. College Composition and Communication, 31, 378-388

Stallard, C.K. (1974). An analysis of the writing behavior of good student writers. Research in the Teaching of English, 8, 206-218.

Taylor, B.P. (1981). Content and written form: A two-way street. TESOL Quarterly, 15, 5-13.

Wall, S., \& Petrovsky, A. (1981). Freshman writers and revision: Results from a survey. Journal of Basic Writing, 3, 109-122.

Wenden, A. (1991). Learner strategies for learner autonomy. London: Prentice-Hall.

Wenden, A.L., \& Rubin, J. (1987). Learner strategies in language learning. Englewood Cliffs, NJ: Prentice-Hall.

Zamel, V. (1982). Writing: The process of discovering meaning. TESOL Quarterly, 16, 195-209.

Zamel, V. (1983). The composing processes of advanced ESL students: Six case studies. TESOL Quarterly, 17, 165-187. 